\title{
Click Reaction Functionalization of Hydroxylated Nanoparticles by Cyclic Azasilanes for Colloidal Stability in Oilfield Applications
}

\author{
Radhika Suresh ${ }^{1}$, Sankaran Murugesan'1, Valery Khabashesku ${ }^{2}$ \\ ${ }^{1}$ Center for Technology Innovation, Baker Hughes, Houston, TX, USA \\ ${ }^{2}$ Department of Materials Science and Nanoengineering, Rice University, Houston, TX, USA \\ Email: radhika.suresh@bakerhughes.com,khval@rice.edu
}

How to cite this paper: Suresh, R., Murugesan, S. and Khabashesku, V. (2021) Click Reaction Functionalization of Hydroxylated Nanoparticles by Cyclic Azasilanes for Colloidal Stability in Oilfield Applications. $A d$ vances in Nanoparticles, 10, 36-49. https://doi.org/10.4236/anp.2021.101003

Received: January 25, 2021

Accepted: February 23, 2021

Published: February 26, 2021

Copyright $\odot 2021$ by author(s) and Scientific Research Publishing Inc. This work is licensed under the Creative Commons Attribution International License (CC BY 4.0).

http://creativecommons.org/licenses/by/4.0/

\begin{abstract}
The growing interest in functionalized nanoparticles and their implementation in oilfield applications (e.g., drilling fluids and enhanced oil recovery (EOR)) facilitate the ongoing efforts to improve their chemical functionalization performance in stabilization of water based or hydrocarbon based nanofluids. Cyclic azasilanes (CAS), substituted 1-aza-2-silacyclopentanes, possess a strained 5-member ring structure. Adjacent $\mathrm{Si}$ and $\mathrm{N}$ atoms in the ring provide opportunity for highly efficient covalent surface functionalization of hydroxylated nanoparticles through a catalyst-free and byproduct-free click reaction. In this work, hydroxylated silica, alumina, diamond, and carbon coated iron core-shell nanoparticles have been studied for monolayer CAS functionalization. Two cyclic azasilanes with different $\mathrm{R}$ groups at $\mathrm{N}$ atom, such as methyl (CAS-1) and aminoethyl (CAS-2), have been utilized to functionalize nanoparticles. All reactions were found to readily proceed under mild conditions (room temperature, ambient pressure) during 1 - 2 hours of sonication. CAS functionalized adducts of hydroxylated nanoparticles have been isolated and their microstructure, composition, solubility and thermal stability have been characterized. As a result, it has been demonstrated, for the first time, that covalent surface modification with cyclic azasilanes can be extended beyond the previously known porous silicon structures to hydroxylated silica, alumina and carbon nanoparticles. The developed methodology was also shown to provide access to the nanoparticles with the hydrophilic or hydrophobic surface functional groups needed to enable oilfield applications (e.g., EOR, tracers, drilling fluids) that require stable water based or hydrocarbon based colloidal systems.
\end{abstract}




\section{Keywords}

Functionalization, Azasilane, Nanoparticles, Colloidal Stability, Oilfield Applications

\section{Introduction}

Colloidal systems of functionalized nanoparticles have been evaluated in oil industry for enhanced oil recovery, formation damage remediation, flow assurance, and water treatment operations [1]-[8]. Surface modified nanoparticles have also been considered for applications as tracers in reservoir studies, active media in thermal management fluids, and fillers in high performance elastomers [9] [10] [11] [12] [13]. Conventional functionalization of nanoparticles, which mostly use alkoxysilanes and chlorosilanes for covalent bonding to surface, need catalytic amount of water for the reactions to proceed, require multiple hours to fully saturate the surface, and release by-products capable of interfering with the desired functional or chemical behavior of the modified surface [14]. Control of monolayer deposition on the nanoparticle surface to obtain a high density of functional groups represents a particularly difficult challenge. The reaction of surface hydroxyl groups with alkoxysilanes normally requires hydrogen bonding of hydroxyl groups with either neighboring hydroxyl groups or the addition of hydrogen-bonding additives such as amines [15]. Alternatively, alkoxysilanes can be first hydrolyzed to silanols, but these silanol-containing species tend to selfpolymerize, generating their own nanoscale domains, often large enough to bridge across features of the treated nanoparticle [16]. Prehydrolyzed silanes are not suitable for vapor phase deposition-the method of choice for most nanoscale applications, since they are not volatile. The most critical intrinsic limitation in reactivity of conventional silanes is the absence of significant thermodynamic driving force for formation of siloxane bonds with substrates.

The increasing demand for surface-modified materials and pigments and functionalized nanoparticles has been driving the continued efforts to improve their chemical coupling performance in critical applications. In response to this demand a new class of chemical compounds, called cyclic azasilanes, has been developed for maximizing the bonding efficiencies to hydroxyl-terminated surfaces. Reactivity of cyclic azasilanes has recently been demonstrated on films, microparticles, and porous silicon particles [17]. Combination of ring strain and unstable Si-N bonding makes the cyclic azasilanes chemically reactive with hydroxyl surfaces through a ring-opening reaction. These compounds are also expected to react with a variety of hydroxyl-functionalized nanoparticles via a ring-opening reaction that is thermodynamically driven without the formation of volatile byproducts, thus proceeding in an environmentally friendly manner. Moreover, cyclic azasilanes offer a higher level of monolayer deposition than traditional organosilane and metal-organics based chemistries, making them suitable as 
coupling agents, surface modifiers and functionalizing tools [17] [18]. However, the literature covering the utility of this approach realized through a mild wet chemistry conditions, has been limited to porous silicon structures [18]. The application of this chemistry to free standing silica and other oxide nanoparticles as well as carbon based nanostructures has not been demonstrated so far.

In this work, we have shown that application of cyclic azasilanes (CAS) that have a strained ring structure with adjacent $\mathrm{Si}$ and $\mathrm{N}$ centers enables a highly efficient functionalization route of a series of different hydroxylated spherical nanoparticles (Scheme 1) proceeding catalyst-free and by-product-free with the exothermic formation of siloxane bonds between the coupling agent and the nanoparticle surface.

The nanoparticles selected for these studies include nanosilica, prepared by colloidal synthesis, alumina, nanodiamond, and carbon coated iron core-shell nanoparticles. Prior to reacting with the cyclic azasilane, the nanoparticles with the carbon surfaces have been hydroxylated by treatment with the appropriate reagents. Two cyclic azasilanes with different $\mathrm{R}$ groups at $\mathrm{N}$ atom, such as methyl (CAS-1) and aminoethyl (CAS-2), have been utilized in the click reactions (Scheme 1) to generate surface functionalities enabling the solubility of nanoparticles either in hydrocarbons or in water.

\section{Materials and Methods}

\subsection{Materials}

All chemicals were used as received, without further purification. Cyclic azasilanes, N-methyl-1-aza-2, 2, 4-trimethyl-2-silacyclopentane (CAS-1) and N-(2aminoethyl)-1-aza-2, 2, 4-trimethyl-2-silacyclopentane (CAS-2) with the purity $>95 \%$ each were purchased from Gelest, Inc. Powders of Silica $(10-20 \mathrm{~nm}$ particle size range) were purchased from SkySping Nanomaterials Inc. and Alumina ( $<50 \mathrm{~nm}$ size of particle aggregates) were obtained from Sigma Aldrich, diamond nanopowder (consisting from $3-6 \mathrm{~nm}$ size primary particles forming up to a micron size aggregates according to TEM) received from NanoAmor, and black powder of Fe@C with 99.5\% purity and $25 \mathrm{~nm}$ average particles size (APS) was purchased from Sigma Aldrich. The solvents, tetrahydrofuran (THF) and dimethylformamide (DMF), were also supplied by Sigma Aldrich.

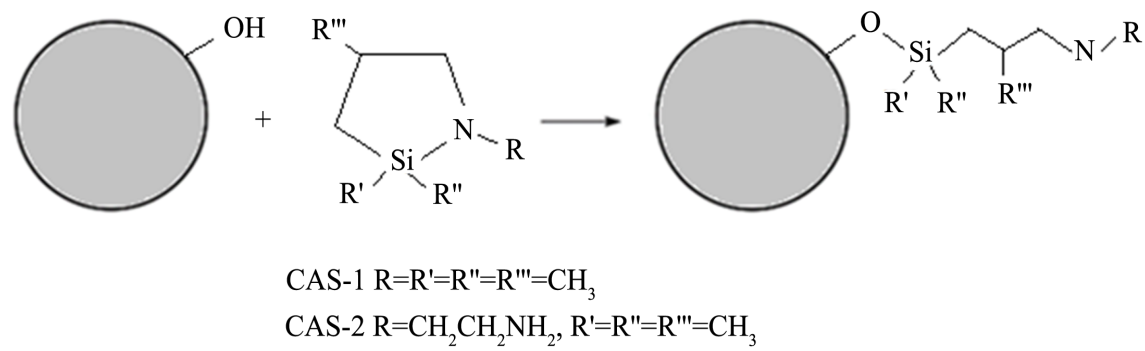

Scheme 1. General representation of click reaction for surface modification of $\mathrm{OH}$-terminated spherical nanoparticles with cyclic azasilanes. 


\subsection{Methods}

\subsubsection{Hydroxylation of Nanoparticles}

Silica and alumina nanoparticles already had a substantial surface coverage by hydroxyl groups in the as received powder form, therefore the hydroxylation was carried out only on diamond and Fe@C nanoparticles.

For nanodiamond, surface hydroxylation by an acid mediated modification of Fenton reaction [19] has been adopted. The schematic representation of the reaction is given in Scheme 2.

In this process $50 \mathrm{~g}$ of nanodiamond $(\mathrm{nD})$ were mixed in a beaker with $250 \mathrm{~g}$ of $\mathrm{FeSO}_{4} \cdot 7 \mathrm{H}_{2} \mathrm{O}$ as the catalyst in $500 \mathrm{~mL}$ of $30 \% \mathrm{H}_{2} \mathrm{SO}_{4}$. This was followed by slow and careful addition of $500 \mathrm{~mL}$ of $\mathrm{H}_{2} \mathrm{O}_{2}$ divided in two equal portions under cooling in an ice bath. After the reaction, product was washed multiple times on the Whatman filter until the $\mathrm{pH}$ of the filtrate reached 4 to 5 range. The increase in the nanodiamond surface coverage by $\mathrm{OH}$ groups was evidenced by FTIR spectrum of freeze-dried sample of the hydroxylated product.

Hydroxylation of carbon shell in Fe@C nanoparticles (Scheme 3) was performed by the following procedure: Fe@C powder was first dispersed by mixing in $35 \% \mathrm{H}_{2} \mathrm{O}_{2}$ and then ultrasonicated for 2 hours. After sonication, the particles were magnetically separated and washed multiple times. Particles separation was carried out with the centrifugation in water-sucrose media using different wt\% concentrations of sucrose $(30 \%, 50 \%$, and $70 \%)$ for $10 \mathrm{~min}$ at $1000 \mathrm{rpm}$.

The particles were collected from the centrifuged top layer, washed with water, and then magnetically separated and re-dispersed in water. After freeze-drying of the $\mathrm{H}_{2} \mathrm{O}_{2}$ treated Fe@C sample, the FT-IR analysis showed the presence of hydroxyl groups.

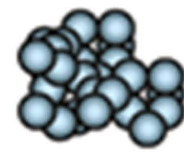

$\mathrm{nD}$

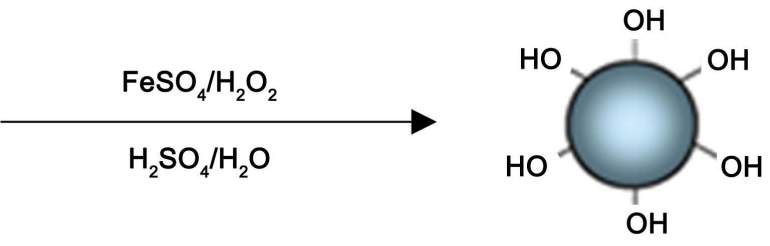

HO-nD

Scheme 2. Surface hydroxylation of diamond nanoparticle aggregates through acid mediated Fenton reaction.

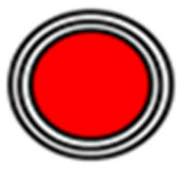

Fe@C

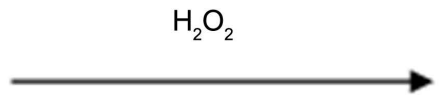

$\mathrm{HO}$

$\mathrm{OH}$

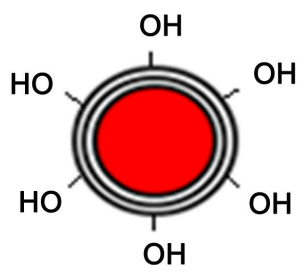

$\mathrm{Fe} @ \mathrm{C}-\mathrm{OH}$

Scheme 3. Surface hydroxylation of carbon coated iron core-shell nanoparticles. 


\subsubsection{Reaction of Hydroxylated Nanoparticles with Cyclic Azasilanes}

Silica, alumina, and hydroxylated diamond were treated with N-methyl-aza-2, 2, 4-trimethyl-2-silacyclopentane (CAS-1) at room temperature by taking $0.03 \mathrm{~g}$ of $\mathrm{SiO}_{2}, 0.05 \mathrm{~g}$ of $\mathrm{Al}_{2} \mathrm{O}_{3}$ each in $5 \mathrm{~mL}$ Toluene, and $0.2 \mathrm{~g}$ of HO-nD in $5 \mathrm{~mL}$ THF. To each mixture, $0.3,0.5$, and $0.2 \mathrm{~mL}$ of CAS-1, respectively, were added and followed by sonication for $1 \mathrm{hr}$. After sonication, the reaction mixtures were washed several times on filter membrane with the same solvent. The residues collected on the filter were placed in ethanol and centrifuged. The precipitates were then dried in vacuum oven at $60^{\circ} \mathrm{C}$.

Similarly, $0.2 \mathrm{~g}$ of Fe@C-OH and HO-nD nanopowders were each taken in 5 mL DMF, each mixed with $0.5 \mathrm{~mL} \mathrm{~N}$-(2-aminoethyl)-aza-2, 2, 4-trimethyl-2silacyclopentane (CAS-2) and then sonicated for 2 hours; thereafter, the reaction product was isolated by filtration and extensive washing on the filter and followed by freeze-drying of the residue collected on the filter.

\subsection{Materials Characterization}

The FTIR spectra of the powder samples were obtained in ATR mode using Thermo Fisher instrument equipped with the diamond ATR accessory. The ATR FTIR spectra of the samples, placed over the diamond crystal surface, were collected at 64 scans with $4 \mathrm{~cm}^{-1}$ resolution. Nanoparticles were analyzed by a field emission Scanning Electron Microscope (SEM) JEOL JSM-7800. For the particle morphology and elemental analysis, the samples were drop casted on a Si wafer substrate and imaged. Elemental analysis was performed by EDS with $15 \mathrm{kV}$ electron beam acceleration energy at working distance of $10 \mathrm{~mm}$. Thermal gravimetric analysis (TGA) was performed using a TA Q500 instrument with Nitrogen as a purge gas at a flow rate of $40 \mathrm{~mL} / \mathrm{min}$ at heating rate of $10^{\circ} \mathrm{C} / \mathrm{min}$ up to $900^{\circ} \mathrm{C}$. The change in weight with temperature was plotted.

\section{Results and Discussion}

\subsection{Hydroxylated Diamond and Fe@C Nanoparticles}

Fenton redox reaction used for synthesis of hydroxylated diamond nanoparticles is highly exothermic, therefore, a controlled addition of $\mathrm{H}_{2} \mathrm{O}_{2}$ to nanodiamond and iron (II) sulfate catalyst in the presence of sulfuric acid is required. Nevertheless, after workup of the reaction mixture, the finally isolated and freeze-dried hydroxylated diamond nanopowder did not contain any iron impurity according to SEM/EDS analysis. As a result, the FTIR spectrum of HO-nD powder (Figure 1(b)) shows prominent bands of the hydroxyl groups bonded to carbon only, such as bands at $3387 \mathrm{~cm}^{-1}$ and $1105 \mathrm{~cm}^{-1}$ due to $\mathrm{O}-\mathrm{H}$ and $\mathrm{C}-\mathrm{OH}$ stretches, respectively.

The hydroxylation of diamond surface facilitates very good dispersability of nanoparticles in water. Photograph in Figure 2 shows a suspension of HO-nD particles that has been stable in water for over two weeks. Water dispersions of HO-nD particles were analyzed through DLS (Figure 2(B)). Analysis yielded 


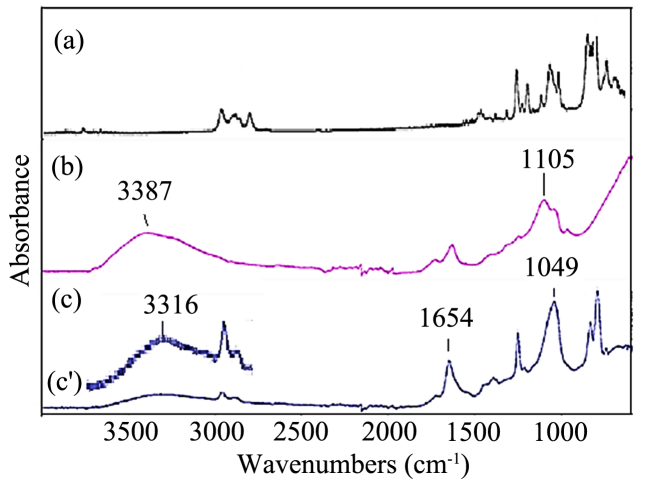

Figure 1. FT-IR spectra of CAS-1 (a) and hydroxylated nanodiamond taken before (b) and after (c) its reaction with CAS-1, showing ( $\left.c^{\prime}\right)$ the expanded along Y-axes section of the spectrum $c$ in the $3700-2800 \mathrm{~cm}^{-1}$ range.

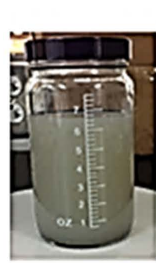

(A)

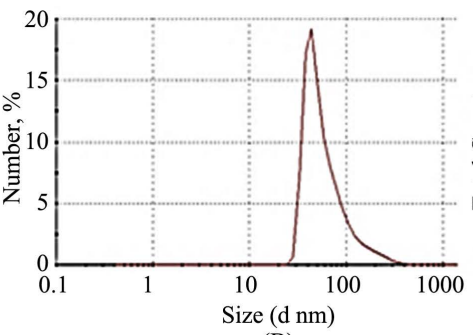

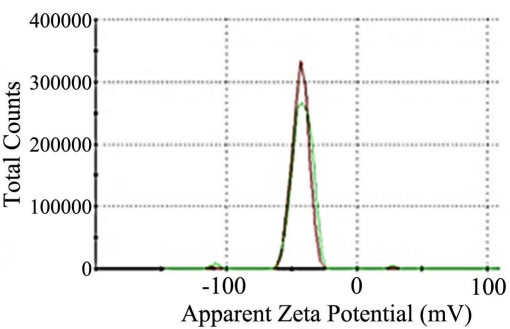

(C)

Figure 2. Photograph of $\mathrm{HO}-\mathrm{nD}$ water dispersion taken after 2 weeks and showing no visual precipitation of the particles (A). DLS measurements data plots for HO-nD particle size distribution (B) and Zeta Potential (C) obtained from two repeated measurements.

mean size of particles aggregated through the surface $\mathrm{OH}$ groups, which is around $64.5 \mathrm{~nm}$. This has substantially decreased in comparison to DLS aggregate's size of $\sim 200 \mathrm{~nm}$ for as-received nanodiamond powder dispersed in water. Surface potential measurements yield zeta potential value of $-42.2 \mathrm{mV}$ (Figure 2(C)). This data confirms the presence of negatively charged hydroxyl functional groups on the surface of nanodiamond particles.

The as-received commercial Fe@C nanopowder is polydispersed with the sizes of the particles ranging from $25 \mathrm{~nm}$ to several microns in diameter according to SEM (not shown). In absence of added surfactants, its dispersion shows very high settling rate in water. However, treatment with $\mathrm{H}_{2} \mathrm{O}_{2}$ turns the carbon surface of these core-shell nanoparticles hydrophilic and, as in the case of nanodiamond, helps to stabilize the suspension. The IR spectrum of Fe@C-OH nanopowder (Figure 3) shows a distinct broad band in the $3000-3500 \mathrm{~cm}^{-1}$ region indicating the introduction of surface $\mathrm{OH}$ groups by hydroxylation.

\subsection{Nanoparticles Functionalized by CAS-1 Coupling Agent}

The click reactions of silica, alumina and HO-nD with the CAS- 1 are expected to result in formation of new $\mathrm{NH}$ bonds in the adducts formed after the CAS ringopening (Scheme 1). Appearance of these bonds can be qualitatively verified by the color reaction typically used for secondary amines with Ninhydrin to form a 


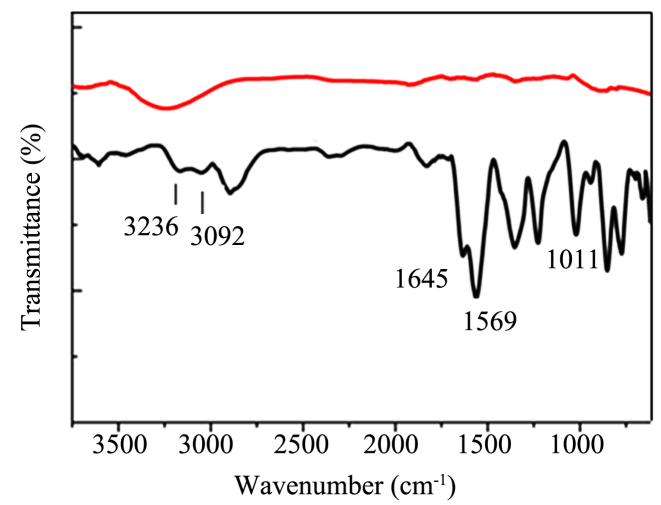

Figure 3. FTIR spectra of Fe@C-OH (red line) and the product of its click reaction with CAS-2 forming amino group terminated product (black line).

yellow colored product [20] [21]. In these tests, nanoparticles of $\mathrm{SiO}_{2}, \mathrm{Al}_{2} \mathrm{O}_{3}$ and HO-nD, acquiring a secondary amine units after functionalization with CAS-1, were each treated with the solution of Ninhydrin in water and heated at $70^{\circ} \mathrm{C}$ for 15 mins. The observed appearance of yellow color indicated the presence of secondary amine. The photographs of the test vials shown on Figure 4 compare the colorless Ninhydrin solution with the formed bright yellow colored suspensions of $\mathrm{SiO}_{2}$-CAS- 1 and $\mathrm{Al}_{2} \mathrm{O}_{3}$-CAS- 1 adducts as well as colloidal suspension of $\mathrm{nD}$ $\mathrm{OH}-\mathrm{CAS}-1$ adduct to Ninhydrin exhibiting brown color. This coloring occurred perhaps due to overlapping and mixing of adduct's yellow color with an intense gray color of initial HO-nD-CAS-1 nanoparticle suspension.

The IR spectra of silica (Figure 5) and nanodiamond (Figure 1) powders showed significant changes after click reactions of their hydroxylated derivatives with the CAS- 1 coupling agent have been completed and the respective adducts Silica-CAS-1 and HO-nD-CAS-1, isolated. They show characteristic bands of the $\mathrm{C}-\mathrm{H}$ stretching and deformation modes in the $2800-3000 \mathrm{~cm}^{-1}$ and $1200-1470$ $\mathrm{cm}^{-1}$ ranges, respectively. New $\mathrm{N}-\mathrm{H}$ and $\mathrm{Si}-\mathrm{O}(\mathrm{C})$ bonds formed as the result of addition and ring opening reactions are best seen in the IR spectrum of HOnD-CAS- 1 adduct through the observation of broad band of NH stretch at 3316 $\mathrm{cm}^{-1}$ (Figure $1\left(\mathrm{c}^{\prime}\right)$ ) and $\mathrm{NH}$ bending mode at $1654 \mathrm{~cm}^{-1}$, and strong band at about $1049 \mathrm{~cm}^{-1}$ due to $\mathrm{Si}-\mathrm{O}(\mathrm{C})$ stretching mode. (Figure $1(\mathrm{c})$ ). In the spectrum of Silica-CAS-1 (Figure 5(b')) the broad band observed near $3310 \mathrm{~cm}^{-1}$ and mid-intensity band at $1670 \mathrm{~cm}^{-1}$ can be associated with the $\mathrm{NH}$ stretch and $\mathrm{NH}$ bending mode, respectively [22].

Less notable changes have been observed in the IR spectrum of aluminaCAS-1 adduct in comparison with the as-received alumina nanopowder and CAS-1 coupling agent (Figure 6). Only weak shoulder peaks belonging to C-H stretching vibrations of $\mathrm{CH}_{3}$ groups have been detected in the $2800-3000 \mathrm{~cm}^{-1}$ region, and several weak bands characteristic for the $\mathrm{CH}\left(1487 \mathrm{~cm}^{-1}\right), \mathrm{HCSi}$ $\left(1260 \mathrm{~cm}^{-1}\right)$ deformation and $\mathrm{NH}\left(1646 \mathrm{~cm}^{-1}\right)$ bending modes were observed in the $1200-1670 \mathrm{~cm}^{-1}$ region (Figure 6(b')). These data likely indicate that in the cases of alumina and hydroxylated nanodiamond the click reaction proceeds less 


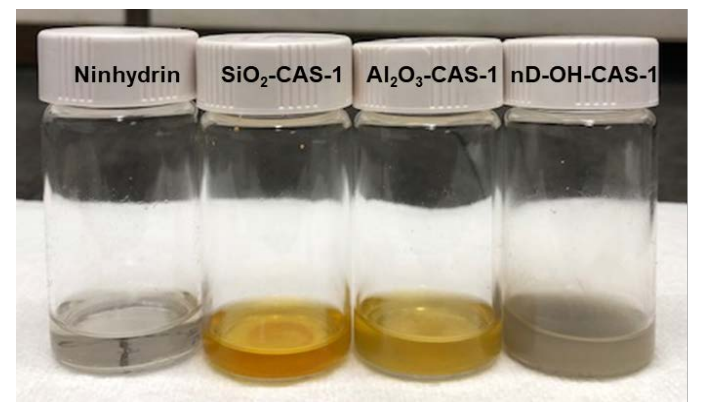

Figure 4. Photographs of Ninhydrin and colored products resulting from its reaction with the CAS-1 adducts to hydroxylated nanoparticles in water.

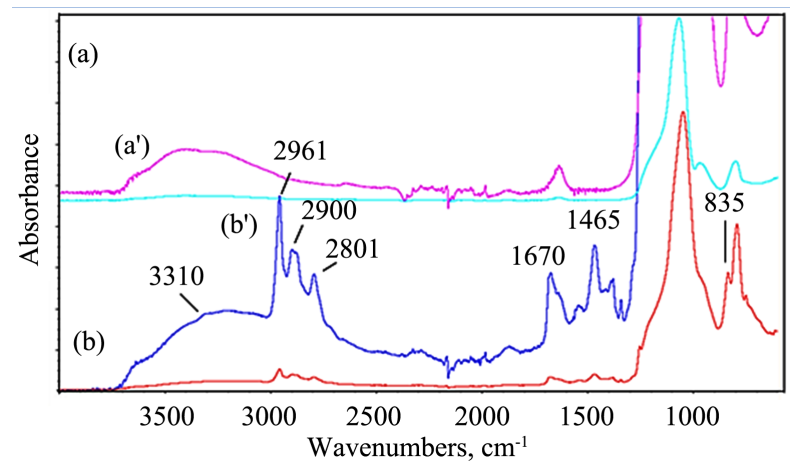

Figure 5. FTIR spectra of silica powder (a), and silica-CAS-1 derivative (b) as well as expanded along Y-axes spectra (a) and (b) shown under (a') and (b') respectively.

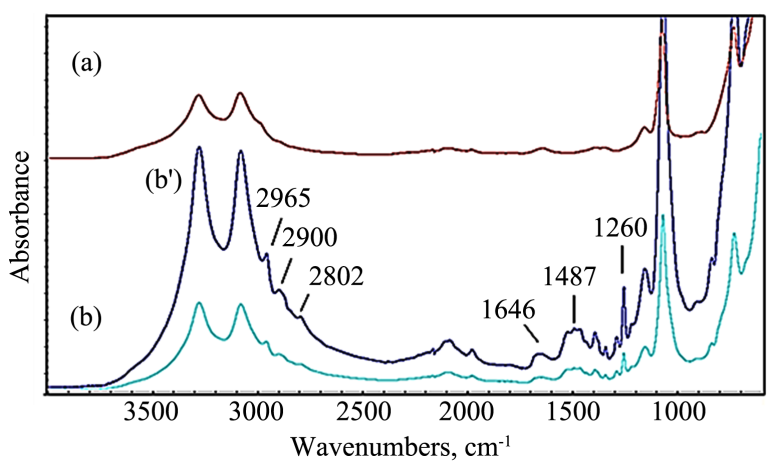

Figure 6. FTIR spectra of as-received alumina powder (a) and $\mathrm{Al}_{2} \mathrm{O}_{3}$-CAS-1 derivative (b) also showing under ( $\left.b^{\prime}\right)$. The expanded along $\mathrm{Y}$-axes spectrum $(\mathrm{b})$.

efficiently than for silica. This observation is confirmed by comparison of TGA data obtained for $\mathrm{HO}-\mathrm{nD}-\mathrm{CAS}-1, \mathrm{SiO}_{2}$-CAS- 1 and $\mathrm{Al}_{2} \mathrm{O}_{3}$-CAS-1 derivatives shown on Figure 7.

The TGA plots (Figure 7) show the estimated weight loss occurring due to degradation of CAS-1 moieties covalently bonded to nanoparticle surface in $\mathrm{SiO}_{2}$ CAS-1, $\mathrm{Al}_{2} \mathrm{O}_{3}$-CAS-1, and HO-nD-CAS-1, of 35, 16, and $12 \mathrm{wt} \%$, respectively, in the $100^{\circ} \mathrm{C}-300^{\circ} \mathrm{C}$ temperature range, as referenced to plot of thermal degradation of neat CAS- 1 occurring in lower temperature range, $100^{\circ} \mathrm{C}-200^{\circ} \mathrm{C}$. Since CAS molecules are covalently bonded to nanoparticles, their thermal degradation occurs at higher temperatures than degradation of free CAS molecules 


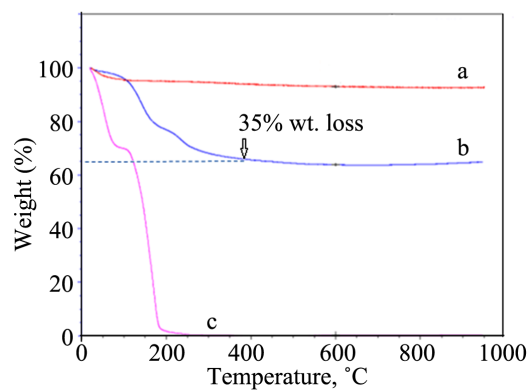

(A)

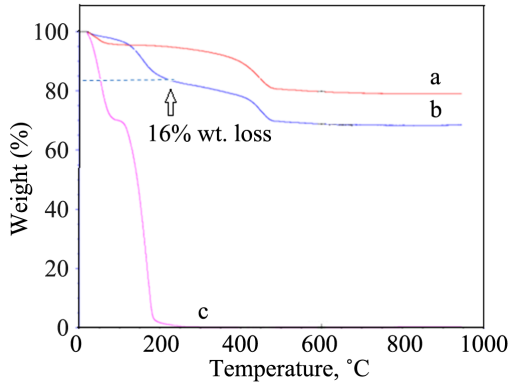

(B)

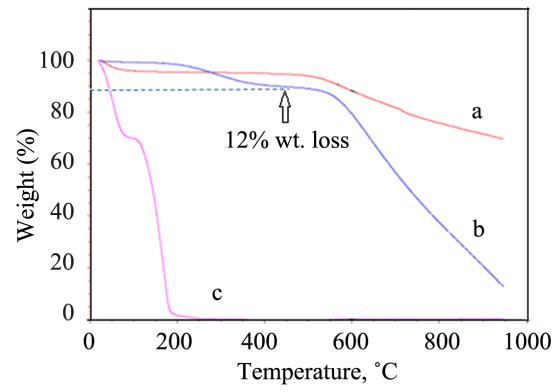

(C)

Figure 7. TGA plots ( $\mathrm{N}_{2}$ flow) of (A): $\mathrm{SiO}_{2}$ nanopowder (a), $\mathrm{SiO}_{2}-\mathrm{CAS}-1$ derivative (b) and CAS-1 (c); (B): $\mathrm{Al}_{2} \mathrm{O}_{3}$ nanopowder (a), $\mathrm{Al}_{2} \mathrm{O}_{3}$-CAS-1 derivative (b), and CAS-1(c); (C): HO-nD nanopowder (a), HO-nD-CAS-1 derivative (b), and neat CAS-1 (c).

as seen on the TGA plots. Usually such observation serves as an indication of the covalent functionalization of the surface of nanoparticle [14].

From these TGA data, the surface grafting density ( $\sigma \mathrm{TGA})$ values were calculated by using the methodology described by Colvin et al. [23]. By taking into consideration the averaged diameters of primary particles, $15 \mathrm{~nm}$ for silica and 6 $\mathrm{nm}$ for alumina and diamond, taken from TEM images provided by vendors for calculation of volume and surface area of individual nanoparticles, then bulk densities of materials were used for calculation of total number of particles and estimation of total surface area. Ultimately, the calculations yielded the following $\sigma$ TGA values (in number of grafted CAS- 1 molecules $/ \mathrm{nm}^{2}$ ): 13.2 for $\mathrm{SiO}_{2}$-CAS-1, 3.0 for $\mathrm{Al}_{2} \mathrm{O}_{3}$-CAS-1, and 2.0 for HO-nD-CAS-1. The calculated differences in surface grafting densities for functionalized nanoparticles indicate a higher surface coverage by CAS- 1 achieved on silica as compared to alumina and nanodiamond. This can be related to higher acidity of surface $\mathrm{O}-\mathrm{H}$ group on silica, resulting in easier $\mathrm{OH}$ bond dissociation and hydrogen atom mobility in silica than in alumina and hydroxylated nanodiamond, which facilitate a more efficient addition of O-H from silica surface across the Si-N moiety in CAS- 1 coupling agent via a click reaction (Scheme 1).

Functionalization of $\mathrm{SiO}_{2}, \mathrm{Al}_{2} \mathrm{O}_{3}$ and $\mathrm{HO}-\mathrm{nD}$ nanoparticles by CAS-1 enable their solubility in hexane which was demonstrated by sonication of $5 \mathrm{mg}$ of each powder in the solvent for $10 \mathrm{~min}$ and photographs taken after $5 \mathrm{~min}$ standing (Figure 8). This very quick proof-of-concept test shows that after the sonication is complete, the non-functionalized particles precipitate immediately while the 


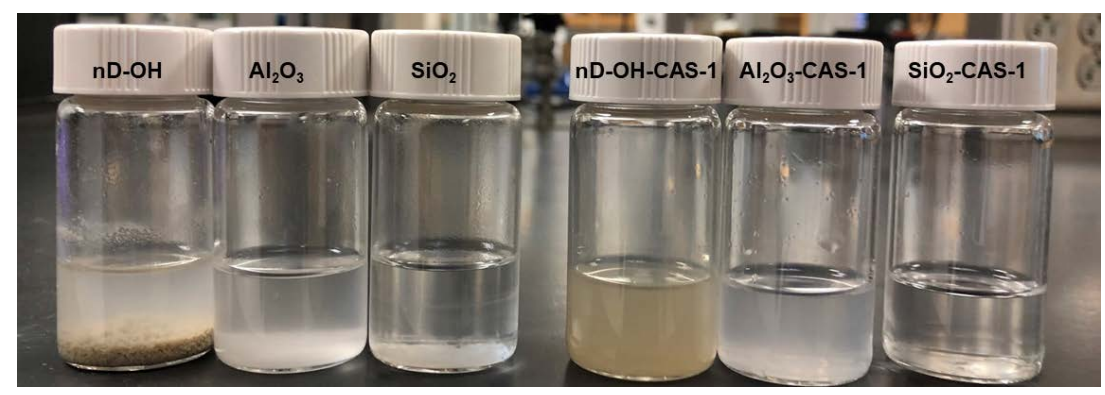

Figure 8. Photographs of vials containing $\mathrm{SiO}_{2}, \mathrm{Al}_{2} \mathrm{O}_{3}$ and $\mathrm{HO}-\mathrm{nD}$, and their CAS-1 functionalized derivatives taken after $10 \mathrm{~min}$ sonication in hexane and $5 \mathrm{~min}$ standing.

CAS-1 treated particles remain suspended in hexane. The higher surface coverage by CAS- 1 in silica aids better colloidal stability of $\mathrm{SiO}_{2}$-CAS- 1 derivative in hexane as compared to hexane dispersions of $\mathrm{Al}_{2} \mathrm{O}_{3}$-CAS- 1 and $\mathrm{HO}-\mathrm{nD}-\mathrm{CAS}-1$ powders which already show some slight precipitation after $5 \mathrm{~min}$ standing (Figure 8).

\subsection{Fe@C-OH and HO-nD Nanoparticles Functionalized by CAS-2 Coupling Agent}

The click reactions of these nanoparticles with CAS-2 ultimately resulted in the formation of primary amine terminated functional groups covalently bonded to surfaces of nanoparticles. The ATR-FTIR spectrum of CAS-2 functionalized Fe@C nanopowder (Figure 3) shows weak bands of $\mathrm{NH}$ and $\mathrm{NH}_{2}$ stretching vibrations in the $3100-3250 \mathrm{~cm}^{-1}$ region and a higher intensity peaks in the 1650 $1550 \mathrm{~cm}^{-1}$ region typical for bending deformation modes of these groups in primary and secondary amines [23].CAS-2 functionalized Fe@C nanoparticles were also characterized through SEM/EDS elemental analysis performed by drop casting the nanoparticles dispersed in ethanol on $\mathrm{Cu}$ substrate. The comparative EDS analysis (Figure 9) taken on the single particle and beside it shows the increased atomic concentration of $\mathrm{C}, \mathrm{N}, \mathrm{O}$, and Si elements in the Fe@C-CAS-2 nanoparticles and allows to conclude that the functionalization of Fe@C nanoparticle surface via its reaction with the cyclic azasilane CAS- 2 indeed took place.

The SEM images also show some increase of the spherical particle sizes for Fe@C-CAS-2 relatively to the as-received F@C nanopowder. This can be most likely related to covalent functionalization of the particle surfaces by about $2 \mathrm{~nm}$ long linear molecular chains of $-\mathrm{OSi}\left(\mathrm{CH}_{3}\right)_{2} \mathrm{CH}_{2} \mathrm{CH}\left(\mathrm{CH}_{3}\right) \mathrm{NHCH}_{2} \mathrm{CH}_{2} \mathrm{NH}_{2}$, resulting from ring opening of CAS-2, and thus capable of adding at least $4 \mathrm{~nm}$ to the diameter of the particles.

The functionalized particles were re-dispersed in DI water for particle size distribution analysis measurement. Initial measurement showed the polydispersity and gave huge error in the measured data. Therefore, these particles were filtered through a $250 \mathrm{~nm}$ Whatman filter membrane. The obtained clear filtrate solution was analyzed for particle size by DLS. The analysis showed the presence of particles with the average size of about $80 \mathrm{~nm}$ (Figure $9(\mathrm{C})$ ). 


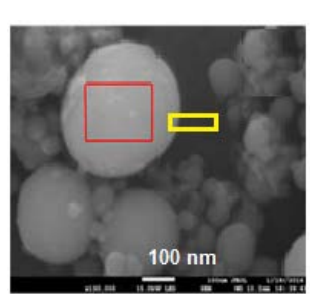

(A)

\begin{tabular}{|l|c|c|}
\hline \multirow{2}{*}{ Element } & \multicolumn{2}{|c|}{ Atomic \% } \\
\cline { 2 - 3 } & $\begin{array}{c}\text { On the } \\
\text { particle }\end{array}$ & $\begin{array}{c}\text { Beside } \\
\text { the } \\
\text { particle }\end{array}$ \\
\hline C K & 32 & 25 \\
\hline N K & 6 & 2 \\
\hline O K & 8 & 6 \\
\hline Si K & 0.2 & 0.1 \\
\hline Fe K & 35 & 13 \\
\hline Cu K & 29 & 52 \\
\hline
\end{tabular}

(B)

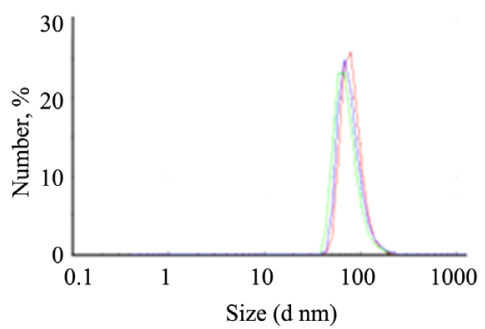

(C)

Figure 9. Analysis of Fe@C-CAS-2 nanoparticles: (A) SEM image; (B) Comparative EDS elemental analysis taken on the spots of single particle (designated by red square) and beside the particle (outlined by yellow rectangle) on SEM image (A); (C) DLS data plots obtained from two repeated measurements on filtrated water solution.

In addition, presence of amino groups on the CAS-2 functionalized Fe@C and diamond nanoparticles has been verified by using the Ninhydrin test [20] [21]. Small amounts of each nanoparticle were treated with Ninhydrin solution and heated to $70^{\circ} \mathrm{C}$ for $15 \mathrm{~min}$, which resulted in coloration of the solutions. However, unlike the CAS-1 functionalized nanoparticles, which contained a secondary amino group and formed a yellow colored adducts with the Ninhydrin, in these tests the appearance of purple/dark violet color has been observed, as shown by photographs on Figure 10, due to presence of terminal primary amine moieties formed as result of click reactions with CAS-2 (Scheme 1).

Having a terminal primary amino group in the functional groups covalently bonded to the nanoparticle surface enable, besides the solubility in polar solvents, also an opportunity for further chemical modifications that can be tailored for particular applications of nanoparticles, e.g., in polymer systems and fluids [1] [2]. For instance, functionalizing the nanoparticles with the fluorescent tags will assist in determination of their placement location when nanoparticle containing fluids are deployed in oil reservoir [9], similar to recently described detectable penetration of tagged magnetic Fe@C nanoparticles inside the living cells [24]. Accordingly, we have used the terminal primary amino group in the structures of HO-nD-CAS-2 and Fe@C-OH-CAS-2 nanoparticles for their modification with the fluorescent marker by coupling to isothiocyanate $-\mathrm{N}=\mathrm{C}=\mathrm{S}$ group containing dye. This has been carried out through treatment of these nanoparticles with $0.005 \mathrm{~g}$ FITC (Fluorescein isothiocyanate) dye in $5 \mathrm{~mL}$ THF at room temperature. Dye treated nanoparticles were washed multiple times with ethanol and acetone to remove the unbonded dye and dried under vacuum. Dried particles were characterized by photoluminescence (PL) emission spectra (Figure 11) taken on powders excited with $365 \mathrm{~nm}$ light.

In the PL spectra, a detectable emission has been observed only from dye treated samples and virtually none from Fe@C-OH-CAS-2 and nD-OH-CAS-2 powders, as indicated by $\mathrm{A} 1$ and $\mathrm{B} 1$ curves on Figure 11. The emission band in nD-OH-CAS-2-dye adduct (curve A2) has broaden and red-shifted by about 30 nm relatively to FITC dye sample. In case of Fe@C-OH-CAS-2-dye, the observed 


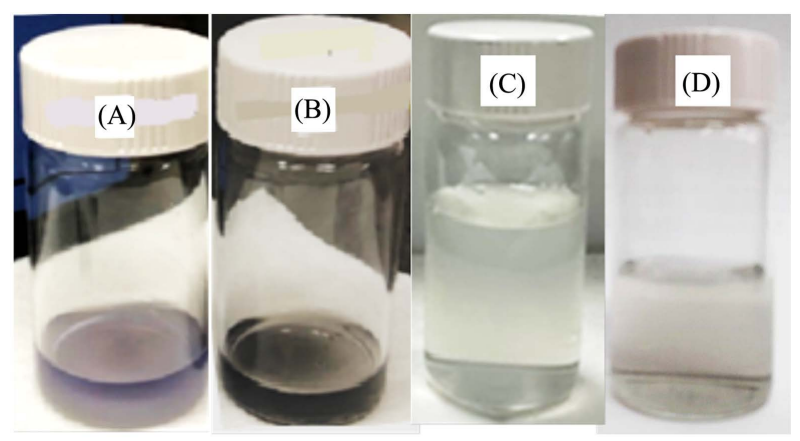

Figure 10. Photographs of vials containing Ninhydrin treated nanoparticles of HO-nDCAS-2 (A) and Fe@C-OH-CAS-2 (B); and non-treated nanoparticles HO-nD-CAS-2 (C); and Fe@C-OH-CAS-2 (D) dispersed in water.

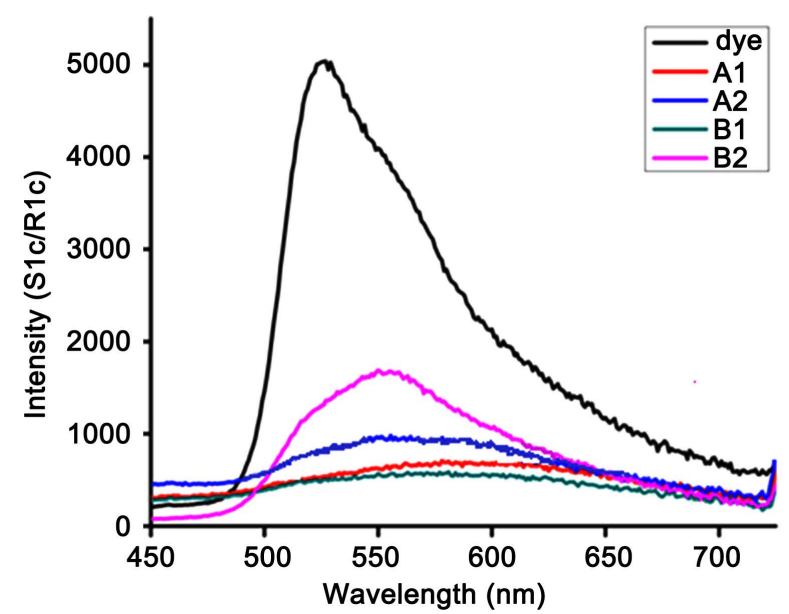

Figure 11. PL spectra of FITC dye (black line), Fe@C-OH-CAS-2 (A1), Fe@C-OH-CAS-2-dye (A2), $\mathrm{nD}-\mathrm{OH}-\mathrm{CAS}-2$ (B1), $\mathrm{nD}-\mathrm{OH}-\mathrm{CAS}-2$-dye (B2).

emission band (curve B2) was very broad and weak, however it showed a maximum similarly red-shifted with respect to emission band of dye itself. These spectral data confirm the transformation of both $\mathrm{NH}_{2}$ groups on nanoparticles and FITC dye after the reaction with the functionalized nanoparticles.

\section{Conclusion}

In summary, the series of experiments described in this work provided a proofof-concept evidence for covalent surface modification of hydroxylated nanoparticles using cyclic azasilanes that can be successfully extended beyond the silicon nanostructures to alumina and carbon nanoparticles, built from $\mathrm{sp}^{3}$ bonded carbon atoms (diamond) and also from the $\mathrm{sp}^{2}$ bonded carbon shell in Fe@C. All studied reactions proceed at especially mild conditions, room temperature, complete in short time and produce no by-products. As a result, such demonstrated facile chemical method utilizing click reactions with either CAS-1 or CAS-2 reagents yielded the nanoparticles surface functionalized with the terminal secondary or primary amino groups. These moieties can particularly serve as anchor points for further modification with the functional groups and enable stable dis- 
persions of nanoparticles in fluids and polymer systems for oilfield applications on demand.

\section{Conflicts of Interest}

The authors declare no conflicts of interest.

\section{References}

[1] Lau, H.C., Yu, M. and Nguyen, Q.P. (2017) Nanotechnology for Oilfield Applications: Challenges and Impact. Journal of Petroleum Science and Engineering, 157, 1160-1169. https://doi.org/10.1016/j.petrol.2017.07.062

[2] Boul, P. and Ajayan, P. (2020) Nanotechnology Research and Development in Upstream Oil and Gas. Energy Technology, 8, Article ID: e1901216. https://doi.org/10.1002/ente.201901216

[3] Rezk, M.Y. and Allam, N.K. (2019) Impact of Nanotechnology on Enhanced Oil Recovery: A Mini-Review. Industrial \& Engineering Chemistry, 58, 16287-16295. https://doi.org/10.1021/acs.iecr.9b03693

[4] Druetta, P., Raffa, P. and Picchioni, F. (2018) Plenty of Room at the Bottom: Nanotechnology as Solution to an Old Issue in Enhanced Oil Recovery. Applied Sciences, 8, 2596-2632. https://doi.org/10.3390/app8122596

[5] Huh, C., Daigle, H., Prigiobbe, V. and Prodanovic, M. (2019) Practical Nanotechnology for Petroleum Engineers. CRC Press, Boca Raton, 366 p. https://doi.org/10.1201/9781351210362

[6] Agrawal, D.K., Kuznetsov, O.V., Suresh, R., Welch, J. and Khabashesku, V.N. (2016) Environment-Friendly Colloidal Nanoparticles for Stabilizing Clays within Subterranean Formations. SPE Annual Technical Conference and Exhibition, Dubai, September 2016, SPE-181641-MS. https://doi.org/10.2118/181641-MS

[7] Kuznetsov, O., Mazyar, O., Agrawal, D., Suresh, R., Feng, X., Behles, J. and Khabashesku, V. (2016) Improved Bitumen Recovery from Mined Oil Sand Ore Using Colloidal Nanosilica. SPE Improved Oil Recovery Conference, Tulsa, April 2016, 179567-MS SPE. https://doi.org/10.2118/179567-MS

[8] Agrawal, D., Xu, K., Darugar, Q. and Khabashesku, V. (2018) Enhanced Oil Recovery by Nanoparticle-Induced Crude Oil Swelling: Pore-Scale Experiments and Understanding. SPE Asia Pacific Oil and Gas Conference and Exhibition, Brisbane, October 2018, SPE-191971-MS. https://doi.org/10.2118/191971-MS

[9] Tayyib, D., Al-Qasim, A., Kokal, S. and Huseby, O. (2019) Overview of Tracer Applications in Oil and Gas Industry. SPE Kuwait Oil \& Gas Show and Conference, Mishref, October 2019, SPE-198157-MS. https://doi.org/10.2118/198157-MS

[10] Cox, J.R., Alsenani, M., Miller, S.E., Roush, J.A., Shi, R., Ow, H., Chang, S., Kmetz, A.A., Eichmann, S.L. and Poitzsch, M.E. (2017) Pyrolyzable Nanoparticle Tracers for Environmental Interrogation and Monitoring. ACS Applied Materials \& Interfaces, 9, 13111-13120. https://doi.org/10.1021/acsami.6b16050

[11] Liu, H., Chika, E. and Zhao, J. (2018) Investigation into the Effectiveness of Nanofluids on the Mini-Channel Thermal Management for High Power Lithium Ion Battery. Applied Thermal Engineering, 142, 511-523. https://doi.org/10.1016/j.applthermaleng.2018.07.037

[12] Dolog, R., Ventura, D., Khabashesku, V. and Darugar, Q. (2017) Nano-Enhanced Elastomers for Oilfield Applications. Offshore Technology Conference, Houston, May 2017, OTC-27609-MS. https://doi.org/10.4043/27609-MS 
[13] Khabashesku, V., Murugesan, S., Dolog, R. and Vasilyev, M. (2020) Effect of Engineered Nanoparticles on Enhancement of Composite Properties Relevant to Oilfield Applications. ACS Applied Materials \& Interfaces, 12, 44215-44224. https://doi.org/10.1021/acsami.0c13981

[14] Pujari, S.P., Scheres, L., Marcelis, T.M.A. and Zuilhof, H. (2014) Covalent Surface Modification of Oxide Surfaces. Angewandte Chemie International Edition, 53, 6322 6256. https://doi.org/10.1002/anie.201306709

[15] Arkles, B., Steinmetz, J.R., Zazyczny, J. and Mehta, P. (1992) Factors Contributing to the Stability of Alkoxysilanes in Aqueous Solution. Journal of Adhesion Science and Technology, 6, 193-206. https://doi.org/10.1163/156856192X00133

[16] Fox, F., Neudörfl J.M. and Goldfuss, B. (2019) Silanediol versus Chlorosilanol: Hydrolyses and Hydrogen-Bonding Catalyses with Fenchole-Based Silanes. Beilstein Journal of Organic Chemistry, 15, 167-186. https://doi.org/10.3762/bjoc.15.17

[17] Arkles, B., Pan, Y., Larson, G.L. and Berry, D.H. (2004) Cyclic Azasilanes: Volatile Coupling Agents for Nanotechnology. In: Mittal, K.L., Ed., Silanes and Other Coupling Agents, Vol. 3, CRC Press, Boca Raton, 179-191.

[18] Kim, D., Zuidema, J.M., Kang, J., Pan, Y., Wu, L., Warther, D., Arkles, B. and Sailor, M.J. (2016) Facile Surface Modification of Hydroxylated Silicon Nanostructures Using Heterocyclic Silanes. Journal of the American Chemical Society, 138, 1510615109. https://doi.org/10.1021/jacs.6b08614

[19] Dunford, H.B. (2002) Oxidations of Iron(II)/(III) by Hydrogen Peroxide: From Aquo to Enzyme. Coordination Chemistry Reviews, 233-234, 311-318. https://doi.org/10.1016/S0010-8545(02)00024-3

[20] Kaiser, E., Colescott, R.L., Bossinger, C.D. and Cook, P.I. (1970) Color Test for Detection of Free Terminal Amino Groups in the Solid-Phase Synthesis of Peptides. Analytical Biochemistry, 34, 595-598. https://doi.org/10.1016/0003-2697(70)90146-6

[21] Odén, S. and von Hofsten, B. (1954) Detection of Fingerprints by the Ninhydrin Reaction. Nature, 173, 449-450. https://doi.org/10.1038/173449a0

[22] Coates, J. (2000) Interpretation of Infrared Spectra, a Practical Approach. In: Meyers, R.A. and McKelvy, M.L., Ed., Encyclopedia of Analytical Chemistry, John Wiley \& Sons Ltd. Chichester, 10815-10837. https://doi.org/10.1002/9780470027318.a5606

[23] Benoit, D.N., Zhu, H., Lilierose, M.H., Verm, R.A., Ali, N., Morrison, A.N., Fortner, J.D., Avendano, C. and Colvin V.L. (2012) Measuring the Grafting Density of Nanoparticles in Solution by Analytical Ultracentrifugation and Total Organic Carbon Analysis. Analytical Chemistry, 84, 9238-9245. https://doi.org/10.1021/ac301980a

[24] Garanina, A., Kireev, I., Zhironkina, O., Strelkova, O., Shakhov, A., Alieva, I., Davydov, V., Murugesan, S., Khabashesku, V., Majouga, A., Agafonov V. and Uzbekov, R. (2019) Long-Term Live Cells Observation of Internalized Fluorescent Fe@C Nanoparticles in Constant Magnetic Field. Journal of Nanobiotechnology, 17, 27-37. https://doi.org/10.1186/s12951-019-0463-5 